\title{
ENTRE DOGMA Y RESISTENCIA: ARMA VERBAL Y REHABILITACIÓN DE LA CONCIENCIA DE MUJER EN LA EROGRAFÍA CONTEMPORÁNEA
}

\author{
Arthur Freddy Fokou Ngouo \\ Universidad de Yaundé I, Camerún
}

\section{RESUMEN}

La presente reflexión enfoca el tema de la revolución feminista desde el área lingüística. Pretendemos mostrar cómo la mujer narradora instrumentaliza el verbo y la expresividad para cuestionar y romper la sistémica desarrollada en torno al falo. Este trabajo investiga, pues, la instrumentalización del signo lingüistico desde una mirada subversiva del discurso machista excluyente. Tomando como base el feminismo decolonial -a tenor de que la matriz colonial es la hija pequeña del «dogma» patriarcal-, procuramos arrojar luz sobre cómo las novelistas se valen de la expresividad erográfica para poner en tela de juicio la autoproclamada soberanía del varón sobre el logos, y al mismo tiempo romper los valores que se han venido atribuyendo al machismo tradicionalmente. Así, este estudio contempla el logos femenino des-censurado de sus coartadas sexistas como un arma de resistencia y de transgresión contra la ideología sustentada por la falocracia a lo largo del tiempo.

PAlabras Clave: arma verbal, erografía, subversión, patriarcado, novela contemporánea.

\author{
BETWEEN DOGMA AND RESISTANCE: \\ VERBAL WEAPON AND REHABILITATION OF WOMAN'S CONSCIOUSNESS \\ IN CONTEMPORARY EROGRAPHY
}

\section{Abstract}

This present reflection focuses on the theme of the feminist revolution from the linguistic area. We intend to highlight how the female narrator instrumentalizes the verb and expressiveness in the search of effects that are usually disruptive of the systemic developed around the phallus. This work investigates, then, the instrumentalization of the linguistic sign from a subversive perspective of the exclusive sexist discourse. Relying on decolonial feminism -given that the colonial matrix is the small daughter of the patriarchal dogma-, we try to shed light on how novelists use erographic expressiveness to question the self-proclaimed sovereignty of men over the logos, and also to break the values that have been traditionally attributed to sexism. Thus, this study contemplates the feminine logos de-censored from its sexist obstacles as a weapon of resistance and transgression against the ideology sustained for a long time by the phalocracy.

KEYWORDs: verbal weapon, erography, subversion, patriarchy, contemporary novel.

DOI: https://doi.org/10.25145/j.refiull.2021.43.06

Revista de Filología, 43; julio 2021, pp. 123-136; ISSN: e-2530-8548 


\section{INTRODUCCIÓN}

En las postrimerías del siglo XviII se producen los primeros focos re-accionarios a la «señoreación» del falo, que había acarreado la erección de una sociedad fuertemente estructurada, cuya jerarquización descansaba en criterios sexuales e incluso raciales. Desde entonces, la revolución feminista ha ido constituyéndose en movimiento de una notable permanencia, que ha logrado resquebrajar las barreras temporales que han representado los 200 años transcurridos, para seguir actuando a principios del siglo Xxi. Que se trate de la ola femenina, feminista o de mujer, que corresponden al feminismo igualitario, radical y al posfeminismo respectivamente, (Showalter 1977), desde que se ha puesto en marcha, la re-acción de la mujer a su primera coartada patriarcal no deja de mover las líneas. En respuesta a la dominación sexista global, la subversión feminista se ha operado en casi todas las áreas de la vida humana, por supuesto en el área lingüística que primero nos ocupa en esta reflexión. Así, la mujer narradora instrumentaliza el verbo y la expresividad, a efectos que suelen ser disruptivos de la sistémica desarrollada en torno al falo. Estas pocas líneas investigan, pues, la instrumentalización del signo lingüistico desde una mirada subversiva del discurso excluyente machista -fálico y colonial-. Descansado en el feminismo decolonial -a tenor de que la matriz colonial es la hija pequeña del «dogma» patriarcal (Dussel 1977: 50)-, procuramos arrojar luz sobre cómo las novelistas se valen de la expresividad erográfica para quebrantar los valores que se han venido atribuyendo al machismo tradicionalmente. Para llevar a cabo nuestro propósito, presentamos diagonalmente la era del encubrimiento machista, antes de obviar el ramalazo feminista en tres erografías ${ }^{1}$ contemporáneas: El cuarto mundo de Diamela Eltit (1988), El llanto de la perra de Guillermina Mekuy (2005) y La rendición ${ }^{2}$ de Toni Bentley (2014).

\section{1. ¿POR QUÉ EL USO DE ARMA Y QUÉ IMPLICA?}

El uso de la palabra arma es muy revelador en este contexto de trabas mentales impuestas por el sistema sexo-género y la moral colonial-cristiana. Comprender la adecuación o inadecuación del uso del lexema arma aquí supone entender bien las causas de su elección. Cuando se actualiza la palabra arma en un discurso, la primera acepción que nos viene a la mente es su carga conflictual. Del latín arma, -orum, el término se aplica al «instrumento, medio o máquina destinados a atacar

${ }^{1}$ La palabra erografía, que se reclama neutral y unificadora, fue acuñada por Brulotte (1998: 6). Nació contra la inestabilidad nocional del erotismo, la sexualidad, la pornografía, y contra el carácter fluctuante, versátil y no ecuánime de esta trilogía.

${ }^{2}$ La edición original en inglés aparece en 2004. Pero en este trabajo nos valdremos de la edición española publicada en 2014. En adelante ECM, ELDLP y LR, respectivamente. Además, la elección de tres novelas nacidas de horizontes culturales disonantes dota de una visión más englobante y universal al texto y su meta. 
o a defenderse» (RAE, 2014). El Diccionario académico nos revela dos vertientes en su conceptualización, las de atacar y defender. Así, un arma puede servir para lanzar un ataque sobre un enemigo y al mismo tiempo para defenderse y protegerse de cualquier enemigo. Esta concepción dual ya nos obliga a preguntarnos por lo que nos mueve a utilizarla a propósito de la contienda ideológica o cultural protagonizada por la mujer en las tres novelas mencionadas. ¿Ataque o defensa? o ¿ataque y defensa? De ser el uno como el otro, ¿cuál sería el enemigo en frente?

\subsection{FiJación históRICA: PROCESO DE ENMASCARAMIENTO GLOBAL}

Esta problematización nos remite directamente al periodo de plenitud de la sociedad patriarcal antes de la aparición de redes realmente revoltosas y contestatarias en su seno, hacia el siglo XVIII. Lerner (1990: 310-311) ha venido presentando el grado de profundidad que tomó el patriarcado cuando pasó de la sociedad comunal, más o menos igualitaria, a la sociedad privada o personal, firmemente desigualitaria, con el comercio organizado en torno a la mujer que era mercantilizada. Levi-Strauss (1985) acuñó el concepto de «intercambio de las mujeres». La dominación profunda a que se refiere la historiadora austriaca se ejerció en todas las esferas de la vida social.

En opinión de Kate Millett (2010), el patriarcado es un sistema total que está en el origen de todo sistema social. En otra formulación, todas las jerarquías sociales (sexual, racial, etc.) de que adolece el mundo hoy en día tienen su caldo de cultivo en la falocracia hegemónica. Además, como reconocen Firestone (1976), Rubin (1986) y Lerner (1990), la subordinación de que fue víctima la mujer a través de su mercantilización en el Neolítico se manifestó primero en el dominio familiar y luego se equiparó y eclosionó en lo social, ya que la familia biológica es la forma institucionalizada del patriarcado, siendo «la única reproductiva básica» (Firestone 1976: 17). Desde luego, la vida de la mujer se convierte en una gran cárcel, cuyo carcelero principal es el hombre, que mientras tanto se hizo varón. Toda su vida a partir del segundo periodo prehistórico que vio florecer agricultura y ganadería puede compendiarse en una palabra, mandada: por el padre, luego por el marido, en fin por la sociedad. Como asevera Bataille (1997: 100): la mujer «se manifiesta en objeto de trabajo doméstico, agrícola y sexual». Esta última era percibida por el imaginario falócrata dominante como una dispensadora del placer, del cual ella misma no podía siquiera gozar (Lo Duca 1970: 13). Su papel en la sociedad resultaba circunscrito en tareas de producción (no remuneradas) y reproducción.

\subsection{ENMASCARAMiento LingüÍ́stico}

Al previo enmascaramiento global, de igual manera, el encubrimiento de la mujer se difunde y opera incluso en el área lingüística. El colapso del Paleolítico supone también el quiebre lingüístico de la mujer, con base en que pierde la palabra y opinión que tenía en el seno de la unidad familiar recién nacida, mediante 
la crianza de los niños. Así, empiezan también los procesos de invisibilización del verbo femenino en la Prehistoria que van a resistir hasta en los tiempos contemporáneos, pese al nacimiento, mientras tanto, de la ola re-accionista femenina, luego feminista. El disfraz echado sobre el verbo va a encubrir tanto la expresión femenina -flexiones y concordancias lingüísticas en femenino van a volverse excluyentes cuando incluyentes y neutras en masculino- como la posibilidad de expresión de la mujer, mediante la aparición del sexismo lingüistico. A este respecto, Lemus (2001: 8) sentencia:

Los idiomas han sido acusados de sexistas por diversos grupos que consideran que la mujer ha sido invisibilizada en la historia por el lenguaje sintético y que su condición de desventaja social frente al hombre se perpetúa a través del lenguaje. Estas afirmaciones se pueden traducir para propósitos de análisis en una hipótesis a la que llamo la Hipótesis del Idioma Sexista o HIS. La HIS clasifica a las sociedades como más o menos sexistas dependiendo del grado de sexismo que contenga el idioma que hablan, si asumimos que el idioma es un reflejo del estado de la mujer en esa sociedad.

Estos recuerdos aclaran la posición subalterna de la mujer y su enmascaramiento en todos los dominios que fue repercutida en el lenguaje. En otros términos, la clasificación sexual que originó la clasificación social fue también el punto de arranque de una jerarquización lingüística que se observa en la sociedad patrilineal histórica y ahora contemporánea.

Estas reflexiones quedan sostenidas por Whorf (1956) y su teoría de la «relatividad lingüística», que sostiene que la estructura lingüística de los idiomas refleja la visión del mundo de sus hablantes, es decir, la estratificación sexual de lo social. La teoría whorfiana tuvo mucho impacto en el mundo académico de su época y lo sigue teniendo en la actualidad. La HIS ${ }^{3}$ de Lemus es solo una de las implicaciones de la teoría whorfiana, ya que relaciona el lenguaje con el statu quo de la mujer y el hombre en la sociedad. Y para ilustrarlo, toma muchos ejemplos:

La HIS hace varias predicciones sobre el lenguaje. Primero, niega la existencia de nombres sintéticos (masculino y femenino), por lo que las palabras sólo pueden tener un significado. Así, cuando decimos «nosotros», estamos excluyendo a las mujeres por lo que tenemos que decir «nosotros y nosotras», o cuando decimos «médicos sin fronteras» estamos diciendo que los que pertenecen a esta organización humanitaria solo son hombres (Lemus 2001: 9).

De esta manera, «a mayor utilización de terminología masculina incluyente en el lenguaje, mayor grado de discriminación de la mujer en la sociedad" (Lemus 2001: 8). La teoría whorfiana y la HIS de Lemus afianzan, pues, una jerarquización lingüístico-sexual que sometía e incluso sigue sometiendo en parte a la mujer en las

${ }^{3}$ La HIS es la «Hipótesis del Idioma Sexista», acuñada por Lemus (2001: 8). 
sombras lingüísticas de la sociedad fálica. Así, como coronación a ese proceso, la palabra se quedó en el varón y el silencio se adueñó de la mujer. Si no podía hablar la mujer en público, tampoco podía decir lo que quería en privado, incluso cuando no se trataba de una cosa proscrita para ella. No podía expresarse de manera libre; el abrir la boca necesitaba imprescindiblemente una etapa previa de análisis y reflexión arduos para así bien discernir lo que debía decirse de lo que no se debía decir. De modo que hablar, cuando se era y se es mujer era y sigue siendo un proceso artificial, controlado y sobre todo muy peligroso porque transgresivo.

Esta vuelta atrás era imprescindible para encontrar solución a la problemática antes enunciada, dado que nos permitió aclarar las responsabilidades de cada uno -hombre y mujer- en el proceso de ataque o defensa que se le adscribe a la palabra arma desde un enfoque definicional. También nos permitió comprender las causas del uso de la palabra arma para calificar la acción devastadora de la mujer a nivel expresivo en los relatos objeto de análisis. Así, en el arma se redescubre simultáneamente una actitud pasiva y activa de la mujer, de defensa y ataque que simbólicamente traduce los dos momentos de sujeción y subversión de la mujer en la historia patriarcal y feminista. De mención obligada es la relación intrínseca entre la moral patriarcal y la moral colonial/cristiana para comprender, después de Escobar (2004: 73) cuando advierte que el discurso moderno es también un discurso masculinista, la inclinación decolonial conferida también a este trabajo: de ahí el giro feminista-decolonial que se opera a lo largo de estas páginas.

\section{EL RAMALAZO VERBAL RE-ACTIVO DE LA MUJER}

Realizadas las aclaraciones anteriores necesarias para la comprensión cabal del uso «arma verbal» o «verbo des-censurado» de las restricciones patriarcales, mostraremos a continuación cómo, en las tres novelas mencionadas, el lenguaje adquiere una función que supera la que por lo regular solemos conferirle.

\section{1. ¿ARMA EUFEMÍSTICA O MANIFESTACIÓN INCONSCIENTE DE TRABAS MENTALES EN ELTit?}

En El cuarto mundo de Diamela Eltit, asistimos a una suavización del lenguaje. La protagonista-narradora no emplea palabras «chocantes» ni «hirientes», quizás para preservar el «pudor» de quienes la lean. Así, sus palabras resultan tapadas por un eufemismo verbal que suele suavizar la comunicación para hacerlas más «convenientes» para la audiencia: «ocurrió una extraña fecundación en la pieza cuando el resto seminal escurrió fuera del borde y sentí como látigo el desecho» (ECM: 83). La mujer-narradora prefiere utilizar palabras mucho más empleadas en las ciencias experimentales, fecundación, para hablar de su relación carnal con su hermano mellizo. Luego, tenemos la ilustración siguiente: «me posee toda la noche, María Chipia me posee toda la noche» (ECM: 87). Aquí, la protagonista-narradora disfraza, otra vez, el sentido real de su comunicación detrás del verbo poseer, que en sí 
no tiene un significado sexual literal, sino figurado. De esta forma, los lectores no perciben directamente lo erótico con el empleo de tal verbo. Poseer en el diccionario patriarcal significa dominar, pues se posee por mediación del falo, paradigma de toda jerarquía sociosexual: "poseer sexualmente, como en francés baiser o en inglés to fuck, es dominar en el sentido de someter a su poder. [...] El mismo acto sexual es concebido por el hombre como una forma de dominación, de apropiación, de "posesión”" (Bourdieu 2000: 33-34, cursiva nuestra). Poseer en esta narración puede ser reemplazado por dominar y conservar todo su sentido: «me [domina] toda la noche, María Chipia me [domina] toda la noche». Los dos enunciados tienen el mismo alcance semántico. La elección de Eltit puede leerse en dos niveles de análisis. Prefiere utilizar poseer en lugar de dominar para primero socavar este sentido que se les confiere al falo y al acto de penetrar, que suelen ser relacionados con la dominación en el horizonte psicomasculino. Haciéndolo, la autora emprende otra ruta terminológica distinta a la impuesta tradicionalmente por el varón. Sin embargo, la sustitución de dominar por poseer y no follar, por ejemplo, aclara otra vez la suavización terminológica que predomina en el relato eltitiano, al no servirse de términos supuestamente "obscenos» como dicen los más conservadores.

A continuación, va este fragmento: «le confieso mi inclinación por el vicio y me abro como una viciosa que hubiera contenido sus apetitos durante demasiado tiempo» (ECM: 99). La elección de la protagonista-narradora de emplear el concepto de vicio y no el de incesto tiene el mismo alcance que los demás indicios textuales: el de evitar herir al público lector. Además, el fragmento "contenido sus apetitos durante demasiado tiempo" puede ilustrar el periodo de invisibilización lingüística a que fue sumida la mujer como mencionábamos antes. A esta fase de sujeción sigue otra de subversión consistente en una revolución en el verbo y la liberación en la expresión de lo que antes se le negaba expresar. Situaciones similares se repiten a lo largo de la trama. He aquí unos fragmentos:

Me ha confesado que su devoción al placer ha abierto las puertas de este desastre (ECM: 103), estoy encima de María Chipia tratando de conseguir el placer. Va y viene. El placer va y viene (ECM: 113), María Chipia, a mi espalda, busca desesperadamente el placer (ECM: 115), heredábamos la casa y la lujuria de la casa que, intermitente, nos invadía (ECM: 121) (cursiva nuestra).

En estos diferentes ejemplos, la protagonista-narradora ni una sola vez llama por su nombre la figura erográfica que lleva a cabo con su hermano mellizo, el incesto. En ningún momento la palabra incesto es empleada en todo el discurso, acaso porque «la nueva moral se endureció y se declararon abominables todos los contactos de la epidermis» (Lo Duca 1970: 38). Como este último autor señala a propósito de los valores "púdicos»:

El censor ha pasado por allí, un censor innoble y sin alma [...]: todo lo había borrado, cercenado, mutilado, alterado, con el pretexto de que el realismo erótico de las obras etruscas no podía ser sino el vestigio de una perversión colectiva, de una plaga purulenta que convenía refrenar (Lo Duca 1970: 18-19). 
Lo único que se emplea son imágenes dulces y alusivas que preservan el «pudor» de la audiencia lectora, convirtiendo el relato de Diamela Eltit en un relato eufemístico cuyo objetivo quizás sea suavizarlo. En otras palabras, la escritora chilena decide narrar una figura sexual sin nombrarla por su nombre, dando a los lectores la posibilidad de hacerlo para ella. Esta elección no es algo exclusivo de El cuarto mundo, sino de casi toda su producción literaria. En realidad, forma parte de algo más grande, del estilo hermenéutico de la latinoamericana, con una escritura fragmentada, como señala Foxler: «el lenguaje de Diamela Eltit perfora la escritura lineal, hace estallar la palabra en mil fragmentos y deja resonando y latiendo una atmósfera inquietante, enrarecida y alucinante» (Foxler 1988: 4), y su cometido principal es trascender las fronteras establecidas para ver lo que está del otro lado, el lado velado por el poder vigente: «y me interesa todo aquello que esté a contrapelo del poder, es decir, la otredad», apunta Diamela Eltit (Foxler 1988: 4). Así, sea cual fuere el poder-patriarcal, colonial o dictatorial-, la chilena lo obstaculiza y, en El cuarto mundo, recurre sobre todo a una letanía incestuosa enmascarada para derrumbarlo.

Dicho esto, lo que se explica como operación suavizadora de la autora latinoamericana puede esconder otro significado que no depende de ella, el fenómeno de autocensura moral. Como se sabe, el patriarcado es un sistema antiguo, con más de dos milenios y medio (Lerner 1990). En otros términos, hace 2500 años que la mujer vive con una coloración masculina de la sociedad metida en las profundidades de su espíritu y conciencia, una coloración re-actualizada durante el periodo colonial que han experimentado los pueblos colonizados. Desgajarse de esta pintura masculina de lo social no siempre es fácil, sobre todo cuando topamos con el área erográfica. En la historia de la humanidad, quizás sea la sexualidad, en general y de la mujer sobre todo la actividad que más se ha controlado y se ha sometido a estereotipos por el poder dominante. El orden vigente antes del advenimiento del erotismo misionado o re-activo, que es una respuesta al mismo, era el orden patriarcal-colonial. Como apunta Leleu (1997: 76), «la Iglesia para controlar mejor la sexualidad, con la mirada en el mantenimiento del poder masculino, condenó todo lo que condujera al placer a la mujer ${ }^{4}$. De esta manera, no siempre es fácil poner el sexo en palabras debido a todas las trabas mentales instaladas inconscientemente. La narración del sexo suele enfrentarse, pues, a una autocensura inconsciente que nos empuja hacia una utilización de formas eufemísticas, de metáforas y símbolos que expresen la erografía de forma indirecta. Y pensamos que la elección de suavización del verbo des-censurado en Eltit encaja totalmente con la autocensura psicomental del sexo, hondo legado de la moral masculina/machista/colonial/cristiana.

\footnotetext{
${ }^{4}$ Véase también Giuseppe Lo Duca (1970); Georges Bataille (1987 y 1997); Michel Foucault (1976), etc.
} 


\subsection{Arma verbal desenfrenada en Bentley y Mekuy}

En lo tocante a La rendición y El llanto de la perra, el grado «hiriente» del verbo des-censurado contrasta visiblemente con el de Eltit en su modo de expresarse. Asistimos a una "de-suavización» lingüística del verbo, que se torna más abrupto en la oralidad expresiva, pero que apunta a una meta similar de quebrantamiento de la matriz fálica. En efecto, Bentley y Mekuy teatralizan la predominancia de una "crudeza» y "violencia» lingüísticas. La norteamericana y la africana recurren a una oralidad «hiriente» que puede «chocar» a los(as) más puritanos(as), para vehicular inequívocamente sus intenciones rupturistas. De manera que en ellas, la trilogía -quién, qué y cómo- se aplica. Quién atañe a las protagonistas-narradoras, que son personajes sumamente erográficos; qué remite al discurso, que de principio a fin se construye en torno al sexo; y cómo a la manera como lo vehiculan, que termina siendo también muy sexual, "crudo» y "provocante».

Bentley abre su novela sin ambages: "la suya fue la primera. En mi culo» (LR: 17). Entre todas las palabras que hubiera podido elegir conforme con el eje vertical o paradigmático, sin embargo, prefiere culo. Esta preferencia de la autora en el inicio nos permite ya vislumbrar el carácter totalmente emancipado del verbo que se instrumentaliza en arma de resistencia. En la literatura femenina de finales del siglo XVIII y de principios del siglo XIX, caracterizada por la linea amoris, no podía ser que se encontrara parecida expresión de alto alcance erográfico. Pero en la contemporaneidad mucho más feminista, la evolución de la «desacralización» verbal por la revolución de la mujer en marcha encuentra un eco favorable en la autora norteamericana. Esta entrada estrepitosa del verbo emancipado permite también atisbar lo que viene a continuación, que aparece sin tardar mucho: «cuando me penetra, aflojo la tensión» (LR: 17). Otra palabra «cruda» y totalmente «a-moral» empleada aquí es penetra, que no deja al pensamiento irse por caminos serpenteados, sino que lo fija directamente en el acto sexual que significa. Cualquier lector frente a penetra sabe de qué se trata y a qué remite. Y la materialización verbal de la pasión eróticosubversiva continúa: "la sodomía es un acto sexual donde la confianza lo es todo» (LR: 17); "en el sexo anal la cooperación es fundamental» (LR: 18). La sodomía, luego el sexo anal, la autora utiliza una sinonimia tanto explícita como desprovista de artífices suavizantes. Los dos sintagmas nominales «chocan» de la misma manera el "pudor» patriarcal de cualquier lector. No viste el lenguaje, sino que lo desviste quizás para dar una tensión profunda a lo que quiere comunicar. El lenguaje participa de su proceso de quebrantamiento de toda la organización masculina cuyo punto culminante es la supuesta "sacralidad» que se despierta en el falo del varón y que antecede y rige la formación de la familia, forma institucionalizada y unidad básica del Estado (Firestone 1976). Y la crudeza se amplifica cada vez más a medida que entramos en la trama de Bentley:

El enculamiento ofrece una resolución espiritual (18), dejándome dar por el culo he aprendido mucho (18), mi anhelo es tan gran [...] que sólo una gran polla hundida hasta el fondo de mi culo puede saciarlo. Él es esa polla. La polla que me salvó (19), veo su polla como un instrumento terapéutico (19), él me folla en mi feminidad (20) (cursiva nuestra). 
Por su expresividad naturalista, sus palabras claras y su estilo relajado, sin tapujos ni formas rebuscadas, Bentley comunica patente y nítidamente sus intenciones a lo largo del relato. Da rienda suelta a sus deseos, sin preocuparse por si ofusca a la gente. Su estilo libre connota una ausencia de miedo y por inferencia una presencia candente de ánimo, valentía y determinación. Logra superar completamente los obstáculos morales y físicos para librarse totalmente de los estereotipos erográficos tradicionales para tener un discurso sexual desenfrenado, compuesto de todas las expresiones que antes le eran prohibidas a la mujer. Su discurso verbal des-censurado se convierte, pues, en un contra-discurso nacido del primer discurso excluyente machista. En ella, la jerarquía sexual desaparece, las fronteras impuestas se resquebrajan antes de pulverizarse, las aguas profundas y el aire cargado de la dinamita patriarcal se disipan y desusan para dar rienda suelta a las pasiones obstruidas desde hace más de dos milenios: «l'érotisme se transforme en un jeu volontaire, un calcul, celui du plaisir» (Bataille 1987: 593).

Parecido destino ocurre en Mekuy con las ilustraciones siguientes:

Sergio me penetró y, mientras lo hacía, Mercedes me acariciaba el pelo y me miraba. Sentía su placer, su felicidad al verme tendida, dominada, mientras susurraba: - ¿lo ves? Todo es tan fácil... el sexo es hermoso (69), no cambiaba nada su aparición, pues me pasaba todos los fines de semana desnuda en sus brazos, pero sus palabras me hicieron sonreír (76), empezaba a estar lejano el tiempo en que me utilizaba y me maltrataba, en que era una pieza sin valor de un juego sexual (77), Sergio estaba penetrando a Mercedes, que estaba tendida sobre la mesa de la cocina, desnuda de medio cuerpo y manchada de mermelada y leche (77), venían a mi cabeza escenas pasadas, los encuentros con Sergio, la voluntad de alejar de mí el sexo (106), todavía soy una adolescente, ¿̇te gusta? -Quería sentir su cuerpo, que me poseyera y poseerle, conocer su sexo. Desabroché su pantalón, tiré de la cremallera y agarré su miembro entre mis manos diciendo-: sólo era esto. (106); -eres un maravilloso objeto sexual pero quiero que seas algo más para mí (108); cerré la puerta de la habitación. Sin mediar palabras, ambos nos sumergimos en un placer incontrolable. Dester me recorrió con la punta de la lengua, desde mi pie a mi cuello, y en frenesí un goce como nunca había conocido, entró en mí superponiendo su sexo al mío. Fundidos, fusionados, sin poder despegarme de él, como si fuera un chicle, sentía que mi piel era su piel y mi cuerpo era suyo (110) (cursiva nuestra).

Estos fragmentos, junto con los que los anteceden, ilustran detalladamente los coitos de las protagonistas de Bentley y Mekuy. Insisten en mostrar detalle tras detalle, fase tras fase, gemido tras gemido, gritos, movimientos, como si estuviéramos ante una película pornográfica. Escalonan sus momentos de placer, de goce, de cara a evidenciar la naturaleza exclusivamente placentera y libertaria de tal "proeza» erótica. Se trata de una verdadera letanía a favor de los efectos «des-censuradores» y gozosos que procura el goce sexual. La heroína-narradora de Mekuy emplea hasta una imagen trivial para representar sus anhelos sexuales, tratándose de perra o perrita, su forma diminutiva: «ansiaba su libertad para volar por el mundo sin necesidad de sacar a la luz la perra que llevo dentro" (ELDLP: 14, cursiva nuestra). Esta expresión abunda en la narración: 
El primer amo de la joven perra en la que pronto me convertiría (30); sin ella me había convertido en una perra necesitada de un amo para sobrevivir (54); dejando salir la perrita que ardía dentro (107); no podía decirle que si ella me convertiría otra vez en una perra vagabunda (164) (cursiva nuestra).

El concepto de perra aquí no remite a ningún animal. Es una figura sígnica para hacer referencia a la sinonimia de la prostituta, esto es, la camelia, ramera o zorra que es según ella. Estas expresiones coloquiales, prohibidas en el discurso masculino, son usadas por la mujer con el objeto de perseguir su meta inicial, la de promover una línea fronteriza entre estos discursos y el suyo, esto es, entre el «Discurso" y un discurso. Así, a modo de repetición, el verbo des-censurado de los corsés erográficos de la "Civilización" se torna un recurso teórico en las manos de las autoras para servir su empresa "procaz» respecto del «Discurso». Esta «brutalidad» expresiva de las autoras nos recuerda el naturalismo presente en casi todas las obras que se adscriben al movimiento feminista, caracterizadas por su re-accionismo verbal frente a los términos que se les prohibían antes.

Para ilustrar, sin pretender hacer un estudio profundo, citemos, entre otras, las obras Arráncame la vida y Como agua para chocolate de Ángeles Mastretta y Laura Esquivel respectivamente. Las dos novelistas suramericanas arrojan luz sobre escenas erográficas liberadas del tabú patriarcal tanto en la forma como en el fondo. Citemos también a Calixte Beyala en Mujer desnuda, mujer negra, donde la heroína lleva una contienda vaginocrática contra el encauzamiento del placer femenino en las sociedades excluyentes, como la machista. Podemos también echar una mirada hacia Pauline Réage, Histoire d'O, en la que notamos una narración del "cuerpo-sexo, sexe, bouche, anus", y en la que el cuerpo-sexo y el verbo se convierten en vehículos ideológicos $^{5}$. A partir del segundo feminismo en las postrimerías del siglo XIX, la crítica feminista mantuvo una línea naturalista y radical, preconizando en sus reclamaciones una expresión propia, independiente y completamente libre de la órbita masculina ${ }^{6}$.

La línea naturalista perseguida por la corriente feminista se aproxima a la de la segunda generación de oro de la literatura española, la del siglo XIx, con figuras insignes como Benito Pérez Galdós, Leopoldo Alas Clarín o Emilia Pardo Bazán. Estos últimos se hicieron famosos por el detallismo escritural entendido como la característica primordial de toda creación literaria. De igual manera, Bentley y Mekuy recurren a un artificio literario parecido, pero en el ámbito expresivo, en su caso. La expresión, como se ha visto antes, aparece tan cruda, libre e incluso «impúdica» para el falocentrismo y la racialización colonial que participa claramente de la doble voluntad de-constructivista protagonizada por las heroínas. En otras palabras, las actrices de las novelistas expresan firmemente su derecho a la «obscenidad», la por-

5 Estos dos últimos ejemplos van referenciados en Bernard Bienvenu Nankeu (2017).

${ }^{6}$ La obra de Kate Millett (2010), Shulamith Firestone (1976), Elaine Showalter (1977 y 1979), Gayle Rubin (1986), Gerda Lerner (1990), Béatrice Didier (1981), Celia Amorós (2010 a y b), Alina Reyes (2005), Simone de Beauvoir (1949), Guerra Cunningham (1981), María Luisa Bombal (2003), Isabel Allende (2009), y muchas otras lo apuntala. 
nografía, la «inmoralidad» como derechos naturales de todos los seres humanos, sea cual fuere su sexo/género. Este derecho a lo «obsceno», pornográfico e «inmoral» es un medio de reivindicación del derecho a una sexualidad des-censurada del doble corsé cultural particularmente para la mujer -re-acciona contra los sistemas falócrata y colonial-, pero también para las antiguas colonias. Y el arma verbal aquí descensurada a través de una lingüística erográfica desenfrenada arroja luz sobre una ruptura de los códigos psicomorales y psicomentales y los tabúes establecidos por la falocracia y la cristiandad, pues saltan el obstáculo moral. De tal modo que, de la primera sujeción fálica, surgió una mujer revolucionaria cuya vida entera estaba dedicada a romper las amarras inútiles que habían limitado sus pasos durante milenios.

Así, aunque aparece en grados distintos, la lingüística de las mujeres narradoras desempeña una doble meta. No solo permite la progresión del relato, sino también se convierte, ella misma, en actante del mismo para incidir mejor en él. El verbo lingüistico resulta des-censurado en las tres narraciones. Materializa la voluntad guerrillera, la valentía o aun la exasperación de las tres narradoras-protagonistas. En otros términos, esta minuciosidad descriptiva revela, una vez más, la intención «impertinente» de las heroínas para con la moral patriarcal que las encierra. Cuestionan repetidamente el paradigma erótico cristiano/machista y sus salidas atrevidas y estrepitosas connotan una ausencia de miedo a todas las represalias, una firmeza enraizada abismalmente. Representa también una voluntad de afirmación y de mostración cuya meta es evidenciar el lado velado, «maravilloso» y sobre todo subjetivo del tabú. Esta última entra en colisión con los principios religiosos vigentes respaldados por el poder dominante. De forma que esta letanía descriptiva forma parte del proyecto, ya formulado antes, de transgresión sistemática de los principios eróticos supuestamente «modernos»/fálicos. Esta concepción de la lingüistica verbal como arma la vemos en Bataille (1997: 103), cuando apunta:

Las palabras groseras que designan los órganos, los productos o los actos sexuales, introducen el mismo rebajamiento. Esas palabras están prohibidas; en general está prohibido nombrar esos órganos. Nombrarlos desvergonzadamente hace pasar de la transgresión a la indiferencia que pone en un mismo nivel lo profano y lo más sagrado.

Y cuando examinamos la actitud de las tres protagonistas-narradoras respecto del lenguaje que promueven en sus narraciones, podemos observar muchas conexiones con el pensamiento bataillano acerca del mismo. En ellas, lo "grosero» supera la transgresión para ingresar en la indiferencia total de la «decencia» vigente en el lenguaje.

\section{CONCLUSIONES}

Estas pocas líneas nos han permitido arrojar luz sobre la profunda tensión erográfica que rige el verbo femenino en las novelas objeto de análisis: El cuarto mundo, El llanto de la perra y La rendición. A lo largo de la deconstrucción, se quita 
paulatinamente el velo que encubre el verbo femenino hasta que se libra totalmente de las coartadas que obstaculizan su andadura libre. El verbo se convierte, pues, en arma o recurso narrativo de cara a implementar el deseo transgresivo de las heroínas. Mediante la escenificación del feminismo decolonial, el sofisticado tinglado lingüístico de las mujeres narradoras desempeña una doble función, aunque el grado de expresividad no consigue homogeneizarse plenamente: por un lado y, como suele hacer, la expresión verbal permite la progresión de la diégesis; por otro lado, se convierte, ella misma, en actante de esta última, a efectos de incidir mejor en ella. De modo que el verbo femenino instrumentalizado se deshace de las trabas «sexistas» que durante decenios han venido ahogando a la mujer año tras año, y aparece descensurado en las erografías investigadas. En otra formulación, las novelistas ponen «relajada» e inequívocamente el sexo "crudo", "grosero» y desenfrenado en palabras, a través de sus heroínas, no por conformismo ni simple querer, tampoco lo hacen para convertir sus relatos en pornogramas, sino que su meta es dar a conocer la ideología revolucionaria que queda invisibilizada detrás del tejido textual. En ellas, se ve un cuestionamiento hondo de la infraestructura sexista, especialmente un parámetro bisagra que protagonizó activa e innegablemente su erección y perennación -el logos-, que durante más de 2500 años quedó como propiedad exclusiva del varón. A través de esta teatralización de la expresividad sexual femenina emancipada, la mujer pone en entredicho, invalidando la "soberanía" autoproclamada y de larga duración que mantuvo el varón sobre dicho logos. Haciéndolo, se compromete en la búsqueda desapasionada de la realidad histórica, sin dejarse equivocar por aseveraciones a-críticamente asumidas o culturalmente construidas. Dicho esto, mediante un diálogo histórico entre épocas diferentes, las novelistas reivindican el derecho de la mujer a la "obscenidad» en la oralidad, desgajándose de las teorías fálicas que operan en contra. Así es como la literatura oralmente pornográfica investiga la remodelación de los comportamientos humanos y, por consiguiente, de la sociedad entera. 


\section{BIBLIOGRAFÍA}

Allende, Isabel (2009): La isla bajo el mar, Barcelona: Random House Mondadori, S.A.

Amorós, Celia (2010a): «La dialéctica del sexo de Shulamith Firestone: Modulaciones feministas del freudo-marxismo", en Celia Amorós y Ana de Miguel (eds.), Teoría feminista: de la Ilustración a la globalización, tomo II, Madrid: Minerva. 69-105.

Amorós, Celia (2010b): «Feminismo y multiculturalismo», en Celia Amorós y Ana de Miguel (eds.), Teoría feminista: de la Ilustración a la globalización, tomo III, Madrid: Minerva. 215-264.

Bataille, Georges (1987): «Les Larmes d'Éros. Dossier des Larmes d’Éros, Dossier de L'Érotisme. Notes-L'Érotisme». Euvres complètes X, Paris: Gallimard.

Bataille, Georges (1997): El erotismo, Barcelona: Tusquets Editores.

Beauvoir, Simone de (1949): Le deuxième sexe, Paris: Gallimard.

Bentley, Toni (2014): La rendición, Buenos Aires: Tusquets Editores.

Beyala, Calixthe (2004): Mujer desnuda, mujer negra, Barcelona: Tusquets editores.

Bombal, María Luisa (2003): Lucía Guerra (comp.), Obra completa, Santiago: Andrés Bello.

Bourdieu, Pierre (2000): La dominación masculina, Barcelona: Editorial Anagrama.

Brulotte, Gaétan (1998): CEuvres de chaires: figures du discours érotique, Paris: L'Harmattan et Les presses de l'Université de Laval.

Didier, Béatrice (1981): L'écriture femme, Paris: PUF.

Dussel, Enrique (1977): Filosofía ética de la liberación III. Niveles concretos de la ética latinoamericana, Buenos Aires: Ediciones Megápolis.

Eltit, Diamela (1988): El cuarto mundo, Buenos Aires: Planeta, Biblioteca del Sur.

Escobar, Arturo (2004): «Mundos y conocimiento de Otro modo. El Programa de Investigación Modernidad/colonialidad», Tábula Rasa. Bogotá. 1. 51-86.

Firestone, Shulamith (1976): La dialéctica del sexo: en defensa de la revolución feminista, Barcelona: Kairós D.L.

Foucault, Michel (1976): Histoire de la sexualité I: la volonté de savoir, Paris: Gallimard.

Foxler, Ana María (1988): «Me interesa todo aquello que está a contrapelo del poder». Entrevista con Diamela Eltit. Suplemento Literatura y Libros. 273, Santiago: Impresiones y Comunicaciones. 4-5. URL: http://www.memoriachilena.gob.cl/602/w3-article-78833.html; 26/06/2017.

Guerra Cunningham, Lucía (1981): «Reflexiones sobre la novela femenina», Hispamérica 28. 29-39.

Leleu, Gérard (1997): Le traité du désir, Paris: Flammarion.

Lemus, Jorge (2001): «Sexismo en el lenguaje: mitos y realidades», Memorias del Encuentro de la Red Centroamericana de Antropología, San Salvador: Asociación Salvadoreña de Antropología. 195-225.

Lerner, Gerda (1990): La creación del patriarcado, Barcelona. Crítica.

Levi-Strauss, Claude (1985): Las estructuras elementales del parentesco, Barcelona: Planeta Agostini.

Lo Duca, Giuseppe (1970): Historia del erotismo, Buenos Aires: Siglo veinte.

Menuy, Guillermina (2005): El llanto de la perra, Barcelona: Plaza y Janés.

Millett, Kate (2010): Política sexual, Madrid. Cátedra. 
NANKeU, Bernard Bienvenu (2017): La figure de l'enseignant collaborateur dans l'érographie contemporaine. URL: https://pdfs.semanticscholar.org/9874/be3e24186711b43f20096490fb149ca23831. pdf?_ga=2.29543423.1101883935.1582257177-1232362402.1582257177; 23/03/2020.

Real Academia Española y Asociación de Academias de la Lengua Española (2014): Diccionario de la lengua española (23. ${ }^{a}$ edición), Madrid: Espasa.

Reyes, Alina (2005): Sept Nuits, Paris: Robert Laffont.

Rubin, Gayle (1986): «El tráfico de mujeres: notas sobre la Economía Política del sexo», Revista Nueva Antropología. VIII. 30. México. 95-145.

Showalter, Elaine (1977): A Literature of their Own, New Jersey: Princeton University Press.

Showalter, Elaine (1979): «Toward a feminist poetics», en P. Rice y P. Waugh (eds.), Modern literary theory. A reader, London: Edward Arnold.

Whorf, Benjamin Lee (1956): "The relation of habitual thought and behavior to language», en J.B. Carrol (ed.), Language, thought and reality: selected writings of Benjamin Lee Whorf, Cambridge: MIT Press. 134-159. 